\title{
Supplementary content
}

\section{Nozzle-jet printed silver/graphene composite based field-effect transistor sensor for phosphate ion detection}

Kiesar Sideeq Bhat, Umesh Tukaram Nakate, Jin-Young Yoo, Yousheng Wang, Tahmineh Mahmoudi, and Yoon-Bong Hahn*

School of Semiconductor and Chemical Engineering, Solar Energy Research Center, Chonbuk National University, 567 Baekjedaero, Deokjin-gu, Jeonju 54896, Republic of Korea

KEYWORDS: Nozzle-jet printing; Ag/rGO hybrid ink; field effect transistor (FET); phosphate ion; large scale production; real water detection; flexible device. 


\section{Ag/rGO}
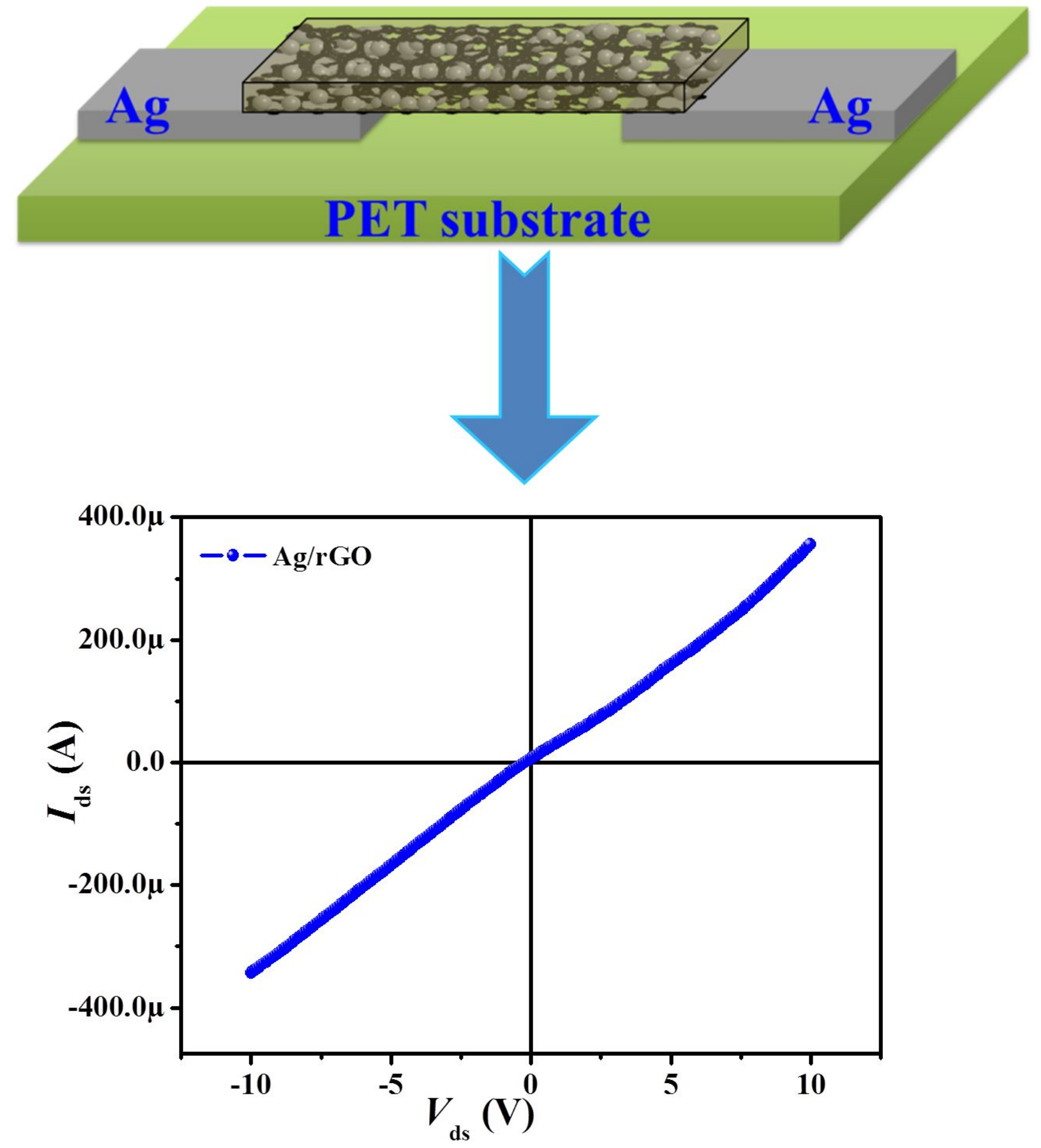

Supplementary Figure S1. $I d s-V d s$ characteristics of Ag/rGO FET sensor device. 

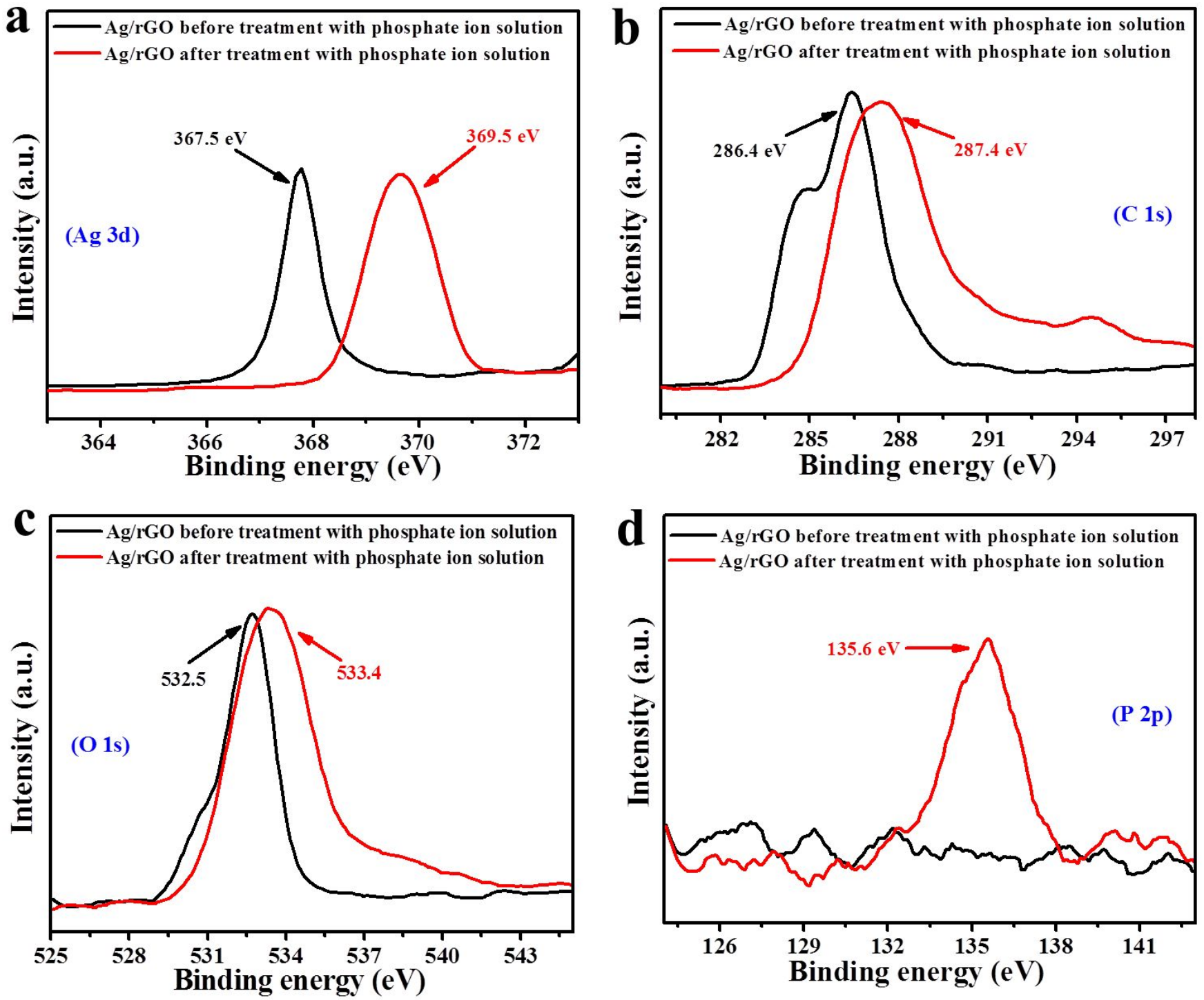

Supplementary Figure S2. XPS spectral analysis of $\mathrm{Ag} / \mathrm{rGO}$ showing the corresponding peaks of various elements present, i.e., $\mathrm{Ag} 3 \mathrm{~d}(\mathrm{a}), \mathrm{C} 1 \mathrm{~s}(\mathrm{~b}), \mathrm{O} 1 \mathrm{~s}(\mathrm{c})$, and P 2p (d). 